\title{
Is something hidden during tachycardia?
}

\author{
D. Mol $^{1}$ (1) • M. T. Rijnierse ${ }^{2}$ - G. S. de Ruiter ${ }^{1}$
}

Published online: 1 September 2016

(C) The Author(s) 2016. This article is available at SpringerLink with Open Access.

a

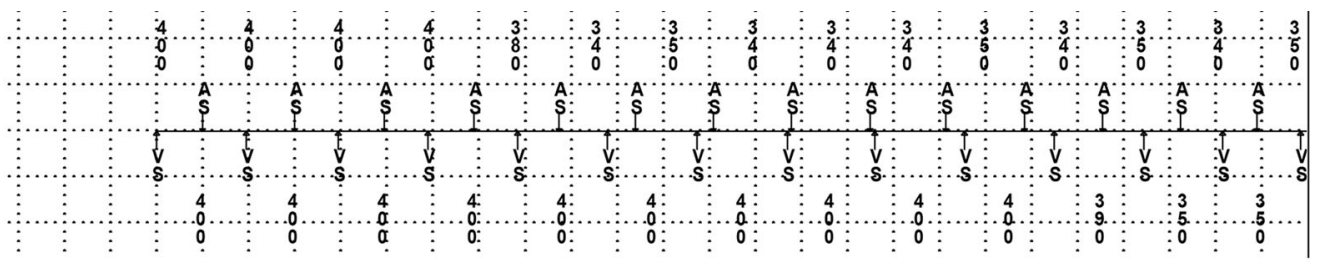

b

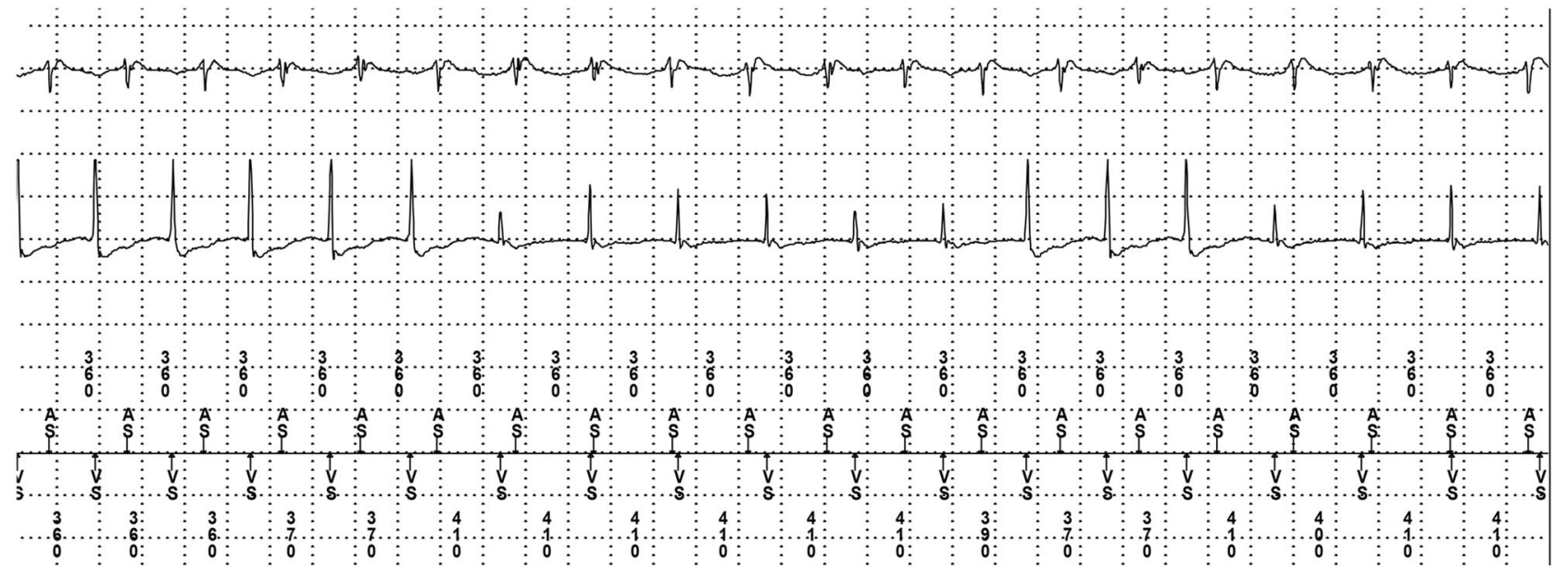

Fig. 1 Intracardiac ICD recording prior to VT ablation; Classified as supraventricular tachycardia

A 61-year-old male patient was referred to our electrophysiology lab for ventricular tachycardia (VT) ablation. The patient had a history of ischaemic cardiomyopathy with impaired left ventricular function and received a dual chamber implantable cardioverter-defibrillator (ICD) after he survived a cardiac arrest. During the past months, the patient

D. Mol

d.mol@olvg.nl

1 Department of Cardiology, OLVG, Amsterdam, The Netherlands

2 Department of Cardiology, VU University Medical Center, Amsterdam, The Netherlands suffered from recurrent episodes of monomorphic VT with appropriate ICD therapies. Electrocardiogram suggested an apical origin of the VT. Prior to VT ablation, device interrogation showed a stored supraventricular tracing (Fig. 1).

Question: Is the device classification appropriate?

Answer: You will find the answer elsewhere in this issue.

Open Access This article is distributed under the terms of the Creative Commons Attribution 4.0 International License (http:// creativecommons.org/licenses/by/4.0/), which permits unrestricted use, distribution, and reproduction in any medium, provided you give appropriate credit to the original author(s) and the source, provide a link to the Creative Commons license, and indicate if changes were made. 